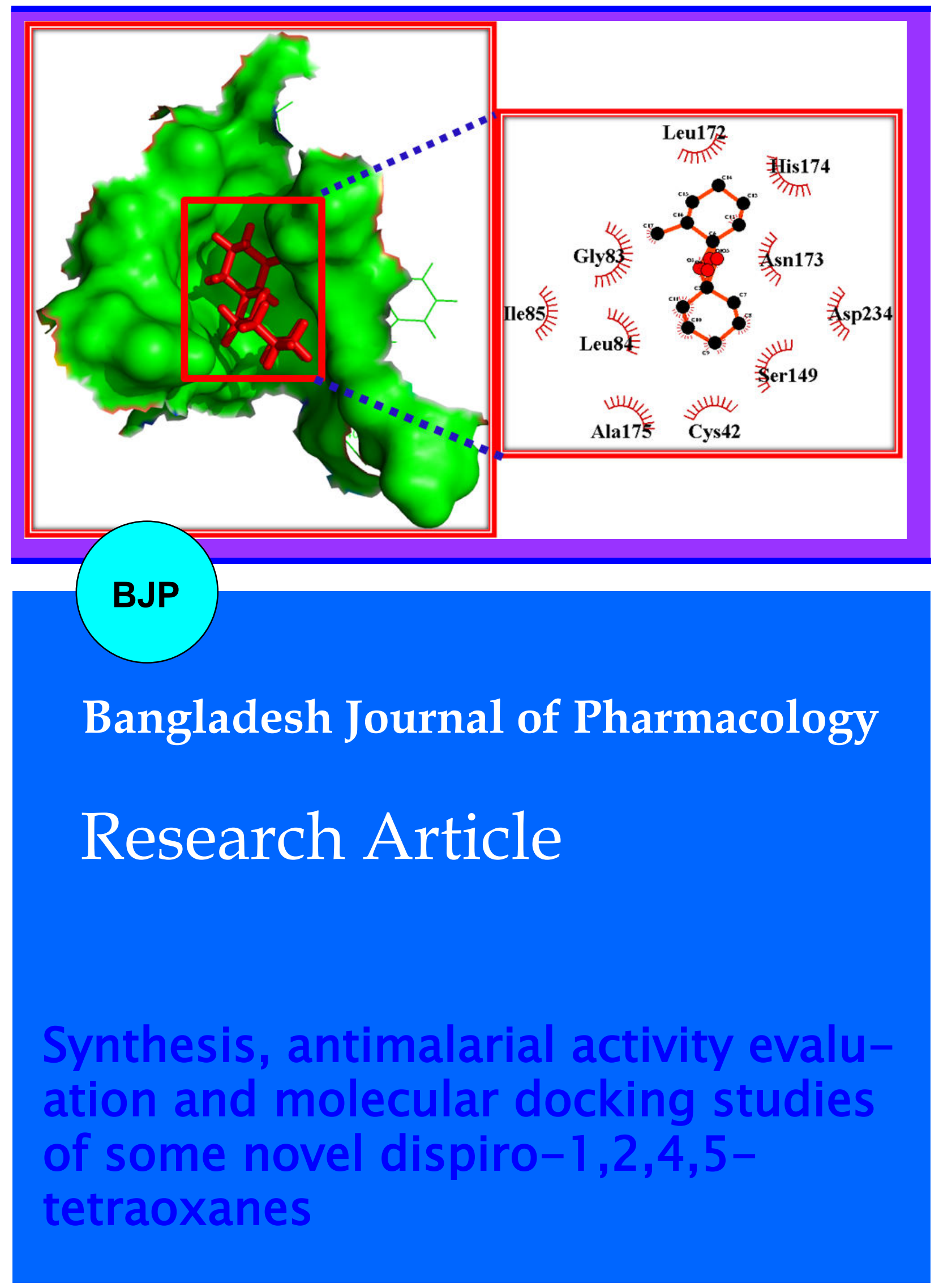


Abstracted/indexed in Academic Search Complete, Agroforestry Abstracts, Asia Journals Online, Bangladesh Journals Online, Biological Abstracts, BIOSIS Previews, CAB Abstracts, Current Abstracts, Directory of Open Access Journals, EMBASE/Excerpta Medica, Global Health, Google Scholar, HINARI (WHO), International Pharmaceutical Abstracts, Open J-gate, Science Citation Index Expanded, SCOPUS and Social Sciences Citation Index;

ISSN: $1991-0088$

\section{Synthesis, antimalarial activity evaluation and molecular docking studies of some novel dispiro-1,2,4,5-tetraoxanes}

\section{Mukesh Kumar Kumawat and Dipak Chetia}

\section{Department of Pharmaceutical Sciences, Dibrugarh University, Dibrugarh 786 004, Assam, India.}

\begin{tabular}{l} 
Article Info \\
\hline Received: $\quad$ 14 August 2015 \\
Accepted: $\quad$ 14 September 2015 \\
Available Online: 6 November 2015 \\
DOI: 10.3329/bjp.v10i4.24532 \\
Cite this article: \\
Kumawat MK, Chetia D. Synthesis, \\
antimalarial activity evaluation and \\
molecular docking studies of some \\
novel dispiro-1,2,4,5-tetraoxanes. \\
Bangladesh J Pharmacol. 2015; 10: 917 \\
-23.
\end{tabular}

\begin{abstract}
Seven novel dispiro-1,2,4,5-tetraoxane derivatives were synthesized and characterized by a number of analytical and spectroscopic techniques. The molecules were subsequently screened for in vitro antimalarial activity against chloroquine resistant strain of Plasmodium falciparum (RKL-9). At antimalarial activity screening, two compounds, namely $5 \mathrm{~d}(\mathrm{MIC}=15.6 \mu \mathrm{g} / \mathrm{mL}$ or 64.5 $\mu \mathrm{M})$ and $5 \mathrm{f}(\mathrm{MIC}=15.6 \mu \mathrm{g} / \mathrm{mL}$ or $54.6 \mu \mathrm{M})$ were found to be about 1.5 times more potent against chloroquine resistant strain-RKL-9 compared to chloroquine $(\mathrm{MIC}=25.0 \mu \mathrm{g} / \mathrm{mL}$ or $78.3 \mu \mathrm{M})$. Molecular docking studies of potent ligands were also performed in cysteine protease binding pocket residues of falcipain-2 as a target protein.
\end{abstract}

\section{Introduction}

Human malaria is a life-threatening disease transmitted by female Anopheles mosquitoes. It is caused by four parasite species of the genus Plasmodium; $P$. vivax, $P$. malariae, $P$. ovale and P. falciparum. P. falciparum is the most pernicious, causing the majority of malaria related morbidity and mortality (Kumawat et al., 2011). WHO reported that 207 million cases of malaria and 627,000 deaths occurred globally in 2012. Most cases (80\%) and deaths (90\%) occurred in Africa, and most deaths (77\%) were in children under 5 years of age.

The growing drug resistance towards $P$. falciparum and the lack of an effective antimalarial vaccine emphasize the need to develop a novel, safe, affordable antimalarial drug effective against multi drug-resistant malaria (Casteel, 1997; O'Neill et al., 2010). Tetraoxanes are believed to have a similar mode of activity as the naturally occurring endoperoxides such as artemisinin ((O'Neill et al., 2008; Vennerstrom et al., 1992, 2000). 1,2,4,5-tetraoxanes have been proven to be superior to other synthetic endoperoxides such as 1,2,4- trioxolanes in terms of stability and to trioxane analogues in terms of both stability and activity (Dong et al., 1999; Amewu et al., 2013).

In the present study, seven molecules of dispiro-1,2,4,5tetraoxanes were synthesized and subsequently screened for their in vitro antimalarial activity against laboratory cultured P. falciparum. These molecules were also tested for their inhibitory potency against falcipain-2 (FP-2).

\section{Materials and Methods}

\section{Chemistry}

All the chemicals used in the work were procured either from Sigma-Aldrich Corporation, USA or Merck Specialties Pvt. Ltd., Mumbai and were used without further purification. The melting points of the synthesized compounds, including intermediate were determined by using Veego-MPI melting point apparatus. The progress of the reactions was monitored on silica gel-G TLC plate using various solvent combinations. The spots were detected with iodine vapors and by observing under UV-light. The UV-visible spectra of 
the synthesized compounds were recorded on UVvisible spectrophotometer (Shimadzu UV-1800). Infrared spectra were recorded on an FT-IR Perkin-Elmer spectrometer. The ${ }^{1} \mathrm{H}$ and ${ }^{13} \mathrm{C}$ NMR spectra were recorded at $400 \mathrm{MHz}$ and $100 \mathrm{MHz}$, respectively, on a Bruker Avance-II 400 NMR spectrometer using either DMSO- $\mathrm{d}_{6}$ or $\mathrm{CDCl}_{3}$ as solvent with tetramethylsilane (TMS) as an internal standard. Mass spectra were obtained on a Waters Q-TOF MICROMA SS LC mass spectrometer. Elemental analyses ( $\mathrm{CHN}$ and $\mathrm{O}$ ) were carried out on Eager Xperience Elemental analyzer (Coates, 2000; Pasto et al., 1992; Mathieson, 1965; Silverstein and Webster, 1963).

\section{General Procedure}

\section{Synthesis of intermediate dihydroperoxides (Step I)}

Cyclic aldehyde/ketone ( $1 \mathrm{~mL}, 10 \mathrm{mmol}$ ) was dissolved at room temperature in a $\mathrm{CH}_{2} \mathrm{Cl}_{2} / \mathrm{CH}_{3} \mathrm{CN}$ mixture (20 $\mathrm{mL}, 1: 3 \mathrm{v} / \mathrm{v})$ followed by $30 \% \mathrm{H}_{2} \mathrm{O}_{2}(10.4 \mathrm{~mL}, 0.1 \mathrm{~mol})$ and $0.5 \mathrm{~mL}$ of concentrated $\mathrm{HCl}$. The reaction mixture was stirred for 2 hours at room temperature and quenched with saturated $\mathrm{NaHCO}_{3}$ and $\mathrm{CH}_{2} \mathrm{Cl}_{2}$. The organic layer was separated, and the water layer was filtered and dried ( $\mathrm{O}^{\prime}$ Neill et al., 2008; Opsenica et al., 2008; Terent'ev et al., 2012).

Synthesis of targeted dispiro-1,2,4,5-tetraoxanes 5 (a-g) (Step II)

Cyclic ketone/aldehyde (0.36 g, $2.3 \mathrm{mmol})$ was added to a cooled solution (ice bath) of dihydroperoxide (0.34 $\mathrm{g}, 2.3 \mathrm{mmol})$ in $\mathrm{CH}_{2} \mathrm{Cl}_{2}(20 \mathrm{~mL})$. The mixture was stirred for $30 \mathrm{~min}$ at the same temperature, and then a cooled $\mathrm{H}_{2} \mathrm{SO}_{4} / \mathrm{CH}_{3} \mathrm{CN}$ mixture $(1.66 \mathrm{~mL}, 1: 10, \mathrm{v} / \mathrm{v})$ was added drop wise. After an additional $50 \mathrm{~min}$ of stirring, the reaction was quenched with saturated $\mathrm{NaHCO}_{3}$ and $\mathrm{CH}_{2} \mathrm{Cl}_{2}$. The organic layer was separated, and the water layer was filtered and dried ( $\mathrm{O}^{\prime} \mathrm{Neill}$ et al., 2008; Opsenica et al., 2008; Terent'ev et al., 2012).

\section{6,7,14,15-tetraoxa-dispiro[4.2.5.2]pentadecane; 5 a}

Brownish semisolid with a characteristic odor; soluble in dichloromethane, DMSO, chloroform; \%yield 43.98; $\mathrm{R}_{\mathrm{f}}$ value 0.81 (petroleum ether: acetone: 1:4); spectroscopic analysis: $\lambda_{\max }\left(\right.$ in $\left.\mathrm{CHCl}_{3}\right) 242.72 \mathrm{~nm}$; FTIR ( $\mathrm{v}_{\max }$, in $\mathrm{cm}^{-1}$, film) 2934.34-2863.53 (C-H stretching, cycloalkyl), 1453.03-1392.73 (C-H bending, cycloalkyl), 1096.82 (C-C -O stretching), 736.74 (peroxide, C-O-O- stretching); ${ }^{1} \mathrm{H}$ NMR (400 MHz, DMSO-d 6 , $\delta$ in ppm) 1.22-1.43 (m, 6H, $3 x>\mathrm{CH}_{2}$, cyclohexyl), 1.46-1.78 $\left(\mathrm{m}, 2 \mathrm{H}, 2 \mathrm{x}>\mathrm{CH}_{2}\right.$, cyclopentyl), 1.81-1.84 (t, $4 \mathrm{H}, \mathrm{J}=12 \mathrm{~Hz}, 2 \mathrm{x}>\mathrm{CH}_{2}$, cyclohexyl), 2.50-2.51 (t, $4 \mathrm{H}, \mathrm{J}=4 \mathrm{~Hz}, 2 \mathrm{x}>\mathrm{CH}_{2}$, cyclopentyl); ${ }^{13} \mathrm{C}$ NMR (100 MHz, DMSO-d 6 , $\delta$ in ppm) 24.96, $25.29(2 \times C$, cyclohexyl), 27.52, 27.61, 27.79, 27.85, 28.46, 29.26 (2xC, cyclopentyl), 30.38, 30.84, 32.08, 33.01, 33.11, 33.68, 33.49 (2xC, cyclohexyl), 38.92 (1xC, cyclohexyl), 39.12, 39.33, 39.54, 39.75, 39.96, 40.17 (2xC, cyclopentyl), 53.93, 60.59,
$63.16,63.38,63.43,78.42,78.75,79.08(1 \times C$, tetraoxane), $172.41,172.54,174.09,174.24$ (1xC, tetraoxane); mass $(\mathrm{m} / \mathrm{z})$ calculated 214.26; observed 246.2 (100\%), 260.2 (94.14\%), 165.2 (79.03\%), 196.2 (73.92\%).

\section{7,8,16,17-tetraoxa-dispiro[5.2.6.2]heptadecane; $5 b$}

Reddish brown semisolid with a characteristic odor; soluble in dichloromethane, DMSO, chloroform; \%yield 15.28; $\mathrm{R}_{\mathrm{f}}$ value (petroleum ether: acetone: 1:3) 0.79; spectroscopic analysis: $\lambda_{\max }\left(\right.$ in $\left.\mathrm{CHCl}_{3}\right) 242.41 \mathrm{~nm}$; FTIR ( $v_{\max }$ in $\mathrm{cm}^{-1}$, film) 2933.37-2862.09 (C-H stretching, cycloalkyl), 1455.48-1349.89 (C-H bending, cycloalkyl), 1044.19 (C-C-O stretching), 855.70-735.23 (peroxide, CO-O- stretching); ${ }^{1} \mathrm{H}$ NMR $\left(400 \mathrm{MHz}, \mathrm{CDCl}_{3}, \delta\right.$ in ppm) 1.18-1.40 (m, 8H, 4x>CH2, cycloheptyl), 1.48-1.88 (m, $6 \mathrm{H}, 3 x>\mathrm{CH}_{2}$, cyclohexyl), 1.97-1.99 (dd, $4 \mathrm{H}, \mathrm{J}=8 \mathrm{~Hz}$, $2 \mathrm{x}>\mathrm{CH}_{2}$, cycloheptyl), 2.00-2.02 (t, $4 \mathrm{H}, \mathrm{J}=8 \mathrm{~Hz}, 2 \mathrm{x}>\mathrm{CH}_{2}$, cyclohexyl); ${ }^{13} \mathrm{C} \mathrm{NMR} \mathrm{(100} \mathrm{MHz}, \mathrm{CDCl}_{3}, \delta$ in ppm) 24.35, 24.58 (2xC, cyclohexyl), 25.53, 28.31(2xC, cycloheptyl), 30.44, 34.14, 43.90 (3xC, cyclohexyl), 64.09, 64.18 (2xC, cycloheptyl), 76.70 (2xC, cycloheptyl), 77.02 (1xC, tetraoxane), $77.34(1 \times C$, tetraoxane).

\section{6,7,15,16-tetraoxa-dispiro[4.2.6.2]hexadecane, $5 c$}

Brownish yellow solid with characteristic odor; soluble in DMSO, dichloromethane, chloroform; melting range 96-97 ${ }^{\circ} \mathrm{C}$; yield 09.96; $\mathrm{R}_{\mathrm{f}}$ value (petroleum ether: acetone: 1:2) 0.65; spectroscopic analysis: $\lambda_{\max }$ (in $\left.\mathrm{CHCl}_{3}\right) 269.30 \mathrm{~nm}$; FTIR ( $\mathrm{v}_{\text {max }}$ in $\mathrm{cm}^{-1}$, film) 2924.122855.05 (C-H stretching, cycloalkyl), 1491.98-1372.76 (C$\mathrm{H}$ bending, cycloalkyl), 1027.81 (C-C-O stretching), 906.12-749.87 (peroxide, C-O-O- stretching); ${ }^{1} \mathrm{H}$ NMR (400 $\mathrm{MHz}, \mathrm{CDCl}_{3}, \delta$ in ppm) 1.18-1.49 (m, 8H, $4 x>\mathrm{CH}_{2}$, cycloheptyl), 1.67-1.74 (m, $4 \mathrm{H}, 2 x>\mathrm{CH}_{2}$, cyclopentyl), 2.32-2.46 (m, $4 \mathrm{H}, 2 \mathrm{x}>\mathrm{CH}_{2}$, cycloheptyl), 2.57-2.60 (t, $4 \mathrm{H}$, $\mathrm{J}=12 \mathrm{~Hz}, 2 \mathrm{x}>\mathrm{CH}_{2}$, cyclopentyl); ${ }^{13} \mathrm{C} \mathrm{NMR}(100 \mathrm{MHz}$, $\mathrm{CDCl}_{3}, \delta$ in ppm) 25.62 (2xC, cyclopentyl), 28.01, 28.10 (2xC, cycloheptyl), 29.71, 40.40 (2xC, cyclopentyl), 76.72, 77.04, 77.36 (2xC, cycloheptyl), 125.50, $125.64(2 \times C$, cycloheptyl), 127.65 (1xC, tetraoxane), 127.97 (1xC, tetraoxane).

\section{1-methyl-7,8,15,16-tetraoxadispiro[5.2.5.2]hexadecane;} $5 d$

Creamy semisolid with a characteristic odor; soluble in dichloromethane, chloroform; \%yield 52.12; $\mathrm{R}_{\mathrm{f}}$ value (isopropyl alcohol: benzene: 1:1) 0.78 ; spectroscopic analysis: $\lambda_{\max }$ (in $\left.\mathrm{CHCl}_{3}\right) 253.48 \mathrm{~nm}$; FTIR ( $\mathrm{v}_{\max }$, in $\mathrm{cm}^{-1}$, film) 2935.02-2861.33 (C-H stretching, methyl and cycloalkyl), 1447.56-1344.27 (C-H bending, methyl and cycloalkyl), 1064.69-952.83 (C-C-O stretching), 846.91758.74 (peroxide, C-O-O- stretching); ${ }^{1} \mathrm{H}$ NMR (400 $\mathrm{MHz}, \mathrm{CDCl}_{3}, \delta$ in ppm) 0.90-0.93 (dd, 3H, J=12Hz, $\mathrm{CH}_{3}$, methylcyclohexyl), 1.02-1.10 (m, 6H, 3x> $\mathrm{CH}_{2}$, cyclohexyl), 1.20-1.32 (m, 6H, 3x> $\mathrm{CH}_{2}$, methylcyclohexyl), 1.38-1.48(m, $4 \mathrm{H}, 2 \mathrm{x}>\mathrm{CH}_{2}$, cyclohexyl), 1.52-1.94 $\left(\mathrm{m}, 2 \mathrm{H},>\mathrm{CH}_{2}\right.$, methylcyclohexyl), 2.27-2.40 (m, 2H, 
$>\mathrm{CH}_{2}$, methylcyclohexyl); ${ }^{13} \mathrm{C}$ NMR $\left(100 \mathrm{MHz}, \mathrm{CDCl}_{3}, \delta\right.$ in $\mathrm{ppm}) 13.66,14.88\left(1 \times \mathrm{C},-\mathrm{CH}_{3}\right.$, methylcyclohexyl), 20.43, 22.59, 22.63 (2xC, cyclohexyl), 22.73, 22.76 (1xC, methylcyclohexyl), 22.82, 23.15 (1xC, methylcyclohexyl), 24.57, 25.26, 25.39 (1xC, methylcyclohexyl), 25.54, 25.57, 25.62 (1xC, methylcyclohexyl), 28.31, 29.48, 29.84, 30.17, 30.40, 30.48, 30.65, 30.89 (3xC, cyclohexyl), $31.09,31.92,32.88,34.15$ (1xC, methylcyclohexyl), 76.70, $77.02,77.34$ (1xC, tetraoxane), 107.53, 107.60, 107.66, $108.04,108.17,109.26,109.72$ (1xC, tetraoxane); mass $(\mathrm{m} / \mathrm{z})$ calculated 242.31; observed 129.1 (100\%), 411.2 (77.20\%), 525.2 (64.55\%), 115.1 (60.78\%), 539.3 (51.53\%), $503.3(47.94 \%), 243.1(47.09 \%)[\mathrm{M}+\mathrm{H}]^{+}$; elemental analysis calculated $\mathrm{C}, 64.44 ; \mathrm{H}, 9.15 ; \mathrm{O}, 26.41$; Observed C, 64.654; H, 9.462; O, 26.620.

9-methyl-6,7,14,15-tetraoxadispiro[4.2.5.2]pentadecane; $5 e$

Brown semisolid with a characteristic odor; soluble in dichloromethane, chloroform; \%yield $10.67 ; \mathrm{R}_{\mathrm{f}}$ value (isopropyl alcohol: benzene: 1:1) 0.74 ; spectroscopic analysis: $\lambda_{\max }\left(\right.$ in $\left.\mathrm{CHCl}_{3}\right) 240.51 \mathrm{~nm}$; FTIR ( $\mathrm{v}_{\max }$, in $\mathrm{cm}^{-1}$, Film) 2927.77-2860.43 (C-H stretching, methyl and cycloalkyl), 1457.38-1375.93 (C-H bending, methyl and cycloalkyl), 1039.11-933.44 (C-C-O stretching), 843.84736.33 (peroxide, $\mathrm{C}-\mathrm{O}-\mathrm{O}$ - stretching).

Ethyl 6,7,14,15-tetraoxadispiro[4.2.5.2]pentadecane-1carboxylate; $5 f$

Orange liquid with a characteristic odor; soluble in dichloromethane, chloroform; boiling range $104-105^{\circ} \mathrm{C}$; \%yield 40.35; $\mathrm{R}_{\mathrm{f}}$ value (benzene: carbon tetrachloride: 2:1) 0.51 ; spectroscopic analysis: $\lambda_{\max }\left(\right.$ in $\left.\mathrm{CHCl}_{3}\right) 253.48$ $\mathrm{nm}$; FTIR ( $\mathrm{v}_{\text {max }}$ in $\mathrm{cm}^{-1}$, Film) 2940.15-2869.23 (C-H stretching, cycloalkyl), $1721.64 \quad(\mathrm{C}=\mathrm{O}$ stretching, $\left.\mathrm{C}_{2} \mathrm{H}_{5} \mathrm{COO}-\right)$, 1455.05-1337.93 (C-H bending, cycloalkyl), 1234.61-1107.91 (-C-O stretching, $\mathrm{C}_{2} \mathrm{H}_{5} \mathrm{COO}-$ ), 1025.47 (C-C-O stretching), 855.46-735.67 (peroxide, C-O-Ostretching); ${ }^{1} \mathrm{H}$ NMR (400 MHz, $\mathrm{CDCl}_{3}, \delta$ in ppm) $1.20-$ $1.22\left(\mathrm{t}, 3 \mathrm{H}, \mathrm{J}=8 \mathrm{~Hz},-\mathrm{CH}_{3}\right.$, ethylcarboxylate), 1.25-1.33 (m, $6 \mathrm{H}, 3 \mathrm{x}>\mathrm{CH}_{2}$, cyclohexyl), 1.35-1.47 (m, $2 \mathrm{H},>\mathrm{CH}_{2}$, cyclopentyl), 1.57-1.76 (m, $4 \mathrm{H}, 2 \mathrm{x}>\mathrm{CH}_{2}$, cyclohexyl), 1.84-1.92 (m, 2H, > $\mathrm{CH}_{2}$, cyclopentyl), 1.96-1.99 (m, 2H, $>\mathrm{CH}_{2}$, cyclopentyl $), 2.28-2.40\left(\mathrm{~m}, 2 \mathrm{H},>\mathrm{CH}_{2}\right.$, cyclopentyl), $4.09-4.38\left(\mathrm{~m}, 2 \mathrm{H},>\mathrm{CH}_{2}\right.$, ethylcarboxylate); ${ }^{13} \mathrm{C}$ NMR (100 MHz, $\mathrm{CDCl}_{3}, \delta$ in ppm) $14.24\left(1 \times \mathrm{C},-\mathrm{CH}_{3}\right.$, ethylcarboxylate), 20.96 (1xC, cyclopentyl), 23.23 (2xC, cyclohexyl), 24.58 (1xC, cyclopentyl), 25.51, 27.39, 28.33 (3xC, cyclohexyl), 34.18 (1xC, cyclopentyl), 38.08 (1xC, cyclopentyl), $38.36\left(1 \times \mathrm{C},-\mathrm{C}_{2} \mathrm{H}_{5}\right.$, ethylcarboxylate), 54.80 $(1 \times C$, tetraoxane), $76.71(1 \times C$, tetraoxane $), 77.02,77.34$ $(1 \times \mathrm{C},-\mathrm{C}=\mathrm{O}$, ethylcarboxylate); mass $(\mathrm{m} / \mathrm{z})$ calculated 286.32; Observed 143.1 (100\%), 115.1 (78.27\%), 111.0 (52.78\%), 157.1 (47.48\%), 407.2 (32.10\%), 129.1 (26.54\%); elemental analysis calculated $\mathrm{C}, 58.73 ; \mathrm{H}, 7.74 ; \mathrm{O}, 33.53$; observed C, 58.784; H, 7.746; O, 33.581.

1-chloro-7,8,15,16-tetraoxadispiro[5.2.5.2] hexadecane;
$5 g$

Yellowish pink semisolid with a characteristic; soluble in methanol, dichloromethane, chloroform; \%yield 09.92; $\mathrm{R}_{\mathrm{f}}$ value 0.82 (petroleum ether: $n$-butanol: 2:1); spectroscopic analysis: $\lambda_{\max }\left(\right.$ in $\left.\mathrm{CHCl}_{3}\right) 242.72 \mathrm{~nm}$; FTIR ( $\mathrm{V}_{\text {max }}$ in $\mathrm{cm}^{-1}$, film) 2940.10-2866.00 (C-H stretching, cycloalkyl), 1435.76-1363.54 (C-H bending, cycloalkyl), 1062.74-961.13 (C-C-O stretching), 809.83-738.60 (peroxide, C-O-O- stretching), 706.26 (-C-Cl stretching, aliphatic- $\mathrm{Cl})$.

\section{Antimalarial activity}

All the synthesized compounds were evaluated for in vitro antimalarial activity against chloroquine resistant strain-RKL-9 of $P$. falciparum ( $P f$ ) using 96 well-microtitre plates at the Department of Pharmaceutical Sciences, Dibrugarh University, Dibrugarh, Assam, India. The laboratory adapted strain of $P f$ was routinely cultured at $37^{\circ} \mathrm{C}$ temperature and $5 \% \mathrm{CO}_{2}$ environment in RPMI 1640 medium supplemented with $25 \mathrm{mM}$ HEPES, $1 \%$ D-glucose, $0.23 \%$ sodium bicarbonate and $10 \%$ heat inactivated human serum. For antimalarial testing, the asynchronous parasites of $P f$ were synchronized to obtain only the ring stage parasitized cells by $5 \%$ D-sorbitol treatment. For carrying out the assay, the initial ring stage parasitemia of $0.8-1.5 \%$ at $3 \%$ hematocrit in a total volume of $100 \mathrm{~mL}$ of medium RPMI-1640 was uniformly maintained. A stock solution $(1 \mathrm{mg} / \mathrm{mL}$ ) of sample was prepared by dissolving the test compounds in DMSO and subsequent dilutions were made with the culture medium. Hundred microlitres of the test compounds at $100 \mu \mathrm{g} / \mathrm{mL}$ concentrations in triplicate was incubated with parasitized cell preparation at $37^{\circ} \mathrm{C}$ and $5 \% \mathrm{CO}_{2}$ in a $\mathrm{CO}_{2}$ incubator. After an incubation period of 36-40 hours, blood smears were prepared from each well and stained with 3\% Giemsa stain. The slides were microscopically observed and the percent dead rings and schizonts were scored against 200 asexual parasites with respect to the control group. Chloroquine was used as the standard reference drug (Trager and Jensen, 1976).

\section{Molecular docking studies}

The three dimensional (3D) crystal structure of falcipain -2 (PDB code 3BPF) was retrieved from the protein data bank (PDB) (Source:www.rcsb.org/pdb). The native autoinducer and all water molecules were removed. The CHARMm force field (FF) was used to add atom types and hydrogens in the proteins. 3D structures of all synthesized compounds were constructed and energy minimized using the Discovery Studio 2.5/ Builder module. Docking studies were performed using the CDOCKER module of Discovery Studio 2.5. CDOCKER is a grid-based molecular docking method where the receptor is held rigid while the ligands are allowed to flex during the refinement. The CHARMm 
force field was used as an energy grid force field for docking and scoring function calculations. Random ligand conformations were generated from the initial structure through high temperature molecular dynamics, followed by random rotations which were further refined by grid-based (GRID 1) simulated annealing and a final grid-based minimization. Of the 10 best poses, one (conformation) having a highest docking score (-CDOCKER energy) was used for the binding energy calculations and further analysis. The higher negative value of CDOCKER energy represents more favorable binding of the complex. This means that ligands with high docking scores are able to fit snugly in the active site pocket with the minimal steric clashes. CDOCKER score (-CDOCKER Energy) includes inter- nal ligand strain energy and receptor-ligand interaction energy, and is used to sort the different conformations of each input ligand (Oliveira et al., 2013; Liu et al., 2012).

\section{Results}

\section{Chemistry}

The targeted compounds were prepared as outlined in Scheme 1 (Steps 1 and 2). The step 1 involved the preparation of intermediates dihydroperoxide (3) by the acid-catalyzed addition of hydrogen peroxide (2) to cyclic carbonyl compounds (1). The step 2 involved the preparation of targeted dispiro-1,2,4,5-tetraoxanes (5)

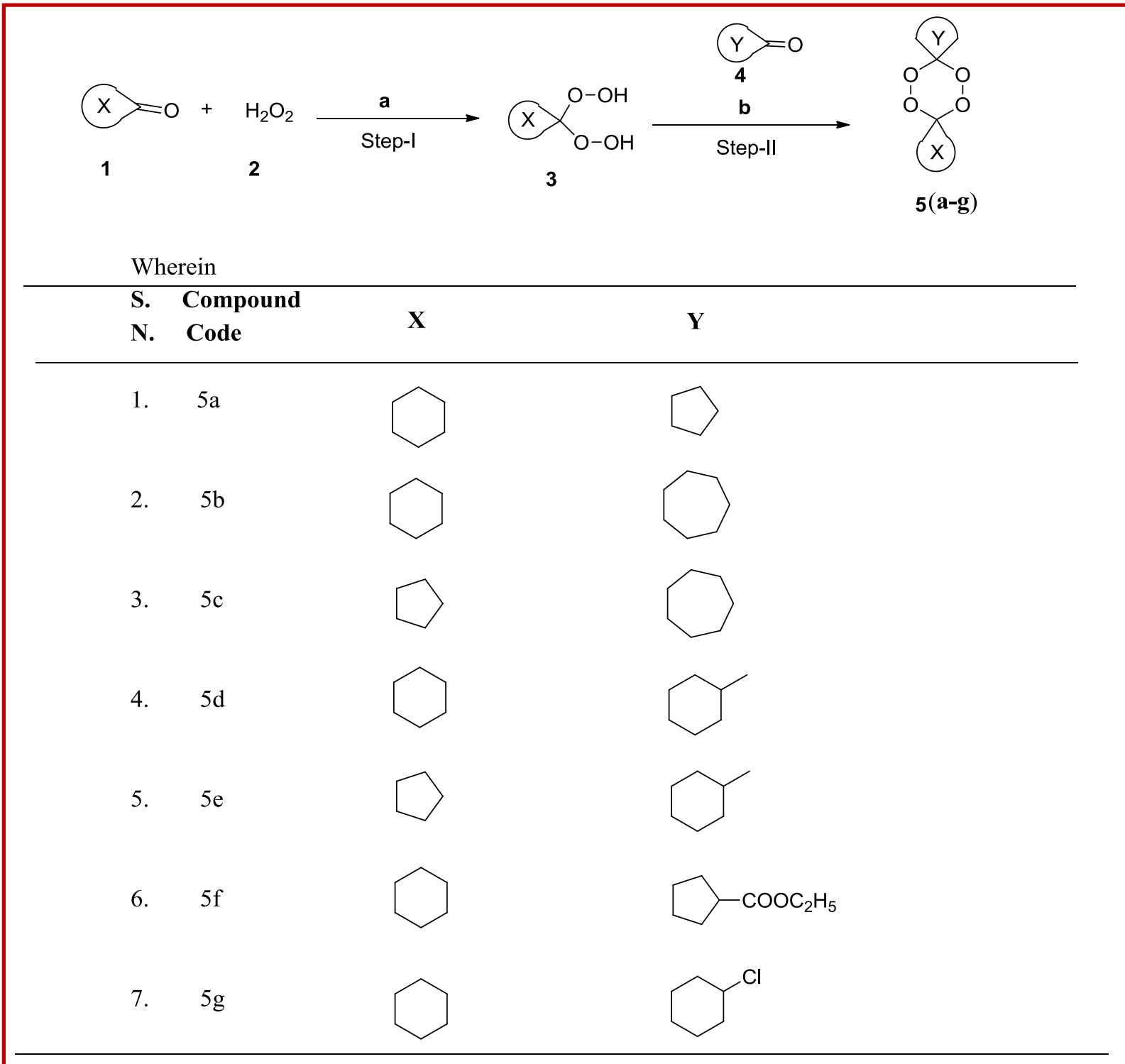

Scheme 1: Synthesis of targeted compounds 5 (5a to $\mathbf{5 g}$ ): Reagents and condition (a,b): Step I: Synthesis of dihydroperoxide (3): a; $\mathrm{CH}_{3} \mathrm{CN}, \mathrm{CH}_{2} \mathrm{CI}_{2}$, Concentrated $\mathrm{HCI}$, stirring at room temperature; Step II: Synthesis of dispiro-1,2,4,5-tetraoxanes (5): b; $\mathrm{CH}_{3} \mathrm{CN}$, $\mathrm{CH}_{2} \mathrm{CI}_{2}$, Concentrated $\mathrm{H}_{2} \mathrm{SO}_{4}$, stirring at $0-10^{\circ} \mathrm{C}$ 
Table I

In vitro antimalarial activity of the synthesized dispirotetraoxanes

\begin{tabular}{|c|c|c|c|c|}
\hline Compound code & $\begin{array}{l}\text { MIC } \\
(\mu \mathrm{M})\end{array}$ & $\begin{array}{c}\text { MIC } \\
(\mu \mathrm{g} / \mathrm{mL})\end{array}$ & $\begin{array}{c}\mathrm{IC}_{50} \\
(\mu \mathrm{g} / \mathrm{mL})\end{array}$ & $\begin{array}{c}\mathrm{IC}_{90} \\
(\mu \mathrm{g} / \mathrm{mL})\end{array}$ \\
\hline $5 a$ & 1166.6 & 250.0 & 3.9 & 9.1 \\
\hline $5 b$ & 257.9 & 62.5 & 3.9 & 6.5 \\
\hline $5 c$ & 273.8 & 62.5 & 3.9 & 38.5 \\
\hline $5 d$ & 64.5 & 15.6 & 3.9 & 12.0 \\
\hline $5 e$ & 547.6 & 125.0 & 3.9 & 88.2 \\
\hline $5 f$ & 54.6 & 15.6 & 3.9 & 3.9 \\
\hline $5 g$ & 958.7 & 250.0 & 4.9 & 146.8 \\
\hline Chloroquine & 78.3 & 25.0 & 0.4 & 1.2 \\
\hline
\end{tabular}

${ }^{*} \mathrm{MIC}, \mathrm{IC}_{50}$ and $\mathrm{IC}_{90}$ values were means of three independent experiments

via cyclization between dihydroperoxide (3) and cyclic carbonyl compounds (4) in the presence of conc. sulfuric acid. The reaction yielded desired pure products though the yields were low.

FT-IR spectra showed the stretching frequency range between region 2850-2950 $\mathrm{cm}^{-1}$ due to aliphatic cycloalkyl -C-H stretching, $1250-1000 \mathrm{~cm}^{-1}$ due to C-C$\mathrm{O}$ stretching and $900-750 \mathrm{~cm}^{-1}$ due to peroxide, $\mathrm{C}-\mathrm{O}-\mathrm{O}-$ stretching. ${ }^{1} \mathrm{H}$ NMR spectra of the compounds showed a triplet or multiplet at $\delta$ (ppm) 1.00-2.50 due to cycloalkyl -C-H which further confirmed the formation of the desired compounds. The analytical and spectral data of the compounds were in conformity with the structure of the synthesized compounds.

\section{Antimalarial activity}

Among the seven compounds, four compounds $5 b, 5 c$, $5 \mathbf{d}$ and $5 \mathrm{f}$ showed good activity against chloroquine resistant Pf strain RKL-9 with MIC $62.5 \mu \mathrm{g} / \mathrm{mL}, 62.5$ $\mu \mathrm{g} / \mathrm{mL}, 15.6 \mu \mathrm{g} / \mathrm{mL}, 15.6 \mu \mathrm{g} / \mathrm{mL}$, respectively and $\mathrm{IC}_{50}$

\begin{tabular}{|ccc|}
\hline \multicolumn{3}{|c|}{ Table II } \\
\hline \multicolumn{3}{|c|}{ Molecular docking interaction results } \\
\hline Compound code & $\begin{array}{c}\text { CDOCKER } \\
\text { energy } \\
(\mathrm{kcal} / \mathrm{mol})\end{array}$ & $\begin{array}{c}\text { CDOCKER inter- } \\
\text { action energy } \\
(\mathrm{kcal} / \mathrm{moL})\end{array}$ \\
\hline $5 \mathrm{a}$ & -1.69 & -28.65 \\
$5 \mathrm{~b}$ & -14.75 & -28.15 \\
$5 \mathrm{c}$ & -23.13 & -28.73 \\
$5 \mathrm{~d}$ & -11.06 & -28.10 \\
$5 \mathrm{e}$ & -2.75 & -34.81 \\
$5 \mathrm{f}$ & -12.96 & -26.82 \\
$5 \mathrm{~g}$ & -8.56 & -37.87 \\
\hline
\end{tabular}

$3.9 \mu \mathrm{g} / \mathrm{mL}$ compared to chloroquine (MIC $25.0 \mu \mathrm{g} / \mathrm{mL}$ and $\left.\mathrm{IC}_{50} 0.4 \mu \mathrm{g} / \mathrm{mL}\right)$. Compounds $5 \mathrm{~d}(\mathrm{MIC}=15.6 \mu \mathrm{g} /$ $\mathrm{mL}$ or $64.5 \mu \mathrm{M})$ and $5 \mathrm{f}(\mathrm{MIC}=15.6 \mu \mathrm{g} / \mathrm{mL}$ or $54.6 \mu \mathrm{M})$ were observed to be about 1.5 times more potent than CQ $(\mathrm{MIC}=25.0 \mu \mathrm{g} / \mathrm{mL}$ or $78.3 \mu \mathrm{M})$ (Table I).

\section{Molecular docking studies}

A molecular docking study was undertaken to gain insight into the key structural requirements and the basis of the distinct activity profile of the test compounds in P. falciparum parasite. The docking studies of the target compounds were performed into the binding pocket of falcipain-2 (PDB code 3BPF). The results and docked conformations of the ligands in the active site are illustrated in Table II and Figure 1, respectively.

\section{Discussion}

Seven novel dispiro-1,2,4,5-tetraoxane derivatives were synthesized and characterized by a number of analytical and spectroscopic techniques. Two compounds, namely $5 \mathrm{~d}(\mathrm{MIC}=15.6 \mu \mathrm{g} / \mathrm{mL}$ or $64.5 \mu \mathrm{M})$ and $5 \mathrm{f}$ ( $\mathrm{MIC}=15.6 \mu \mathrm{g} / \mathrm{mL}$ or $54.6 \mu \mathrm{M}$ ) were found to be about 1.5 times more potent against chloroquine resistant strain-RKL-9 compared to chloroquine (MIC $=25.0 \mu \mathrm{g} /$ $\mathrm{mL}$ or $78.3 \mu \mathrm{M})$ on antimalarial activity screening. Molecular docking study results showed that the targeted molecules were snugly fitted into the active site with considerable and diverse CDOCKER energy (1.6870 to -23.1300 ) with FP-2 along with the formation of numerous hydrogen bonds and hydrophobic interactions.

Vennerstrom and co-workers (1992) reported that high 


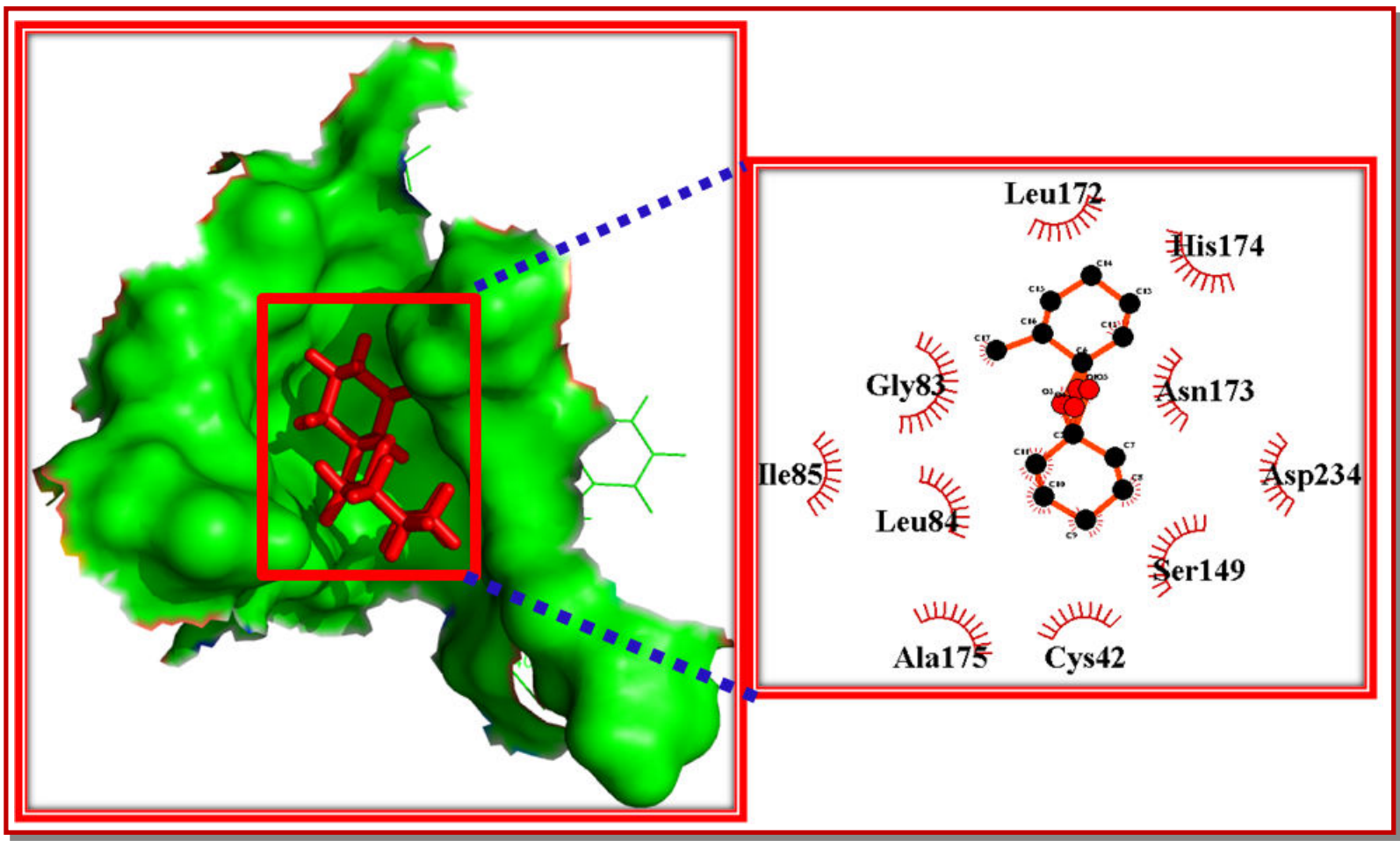

Figure 1: Docked complex of compound $5 \mathrm{c}$ in the binding pocket of FP-2

steric hindrance close to the peroxide ring is unfavorable for activity in dispirotetraoxanes. Amewu and co-workers (Amewu et al., 2013) reported that dispirotetraoxane compounds was found to be equally potent as artemisinin.

Antimalarial activity results reflect that the dispirotetraoxanes are found to be potent compounds against chloroquine resistant Pf strain RKL-9. Substitution on dispirocycloalkane-tetraoxane with methyl and ethyl carboxylic acid groups make more active tetraoxanes than CQ against RKL-9 as observed with $\mathbf{5 d}$ and $\mathbf{5 f}$, due to desirable lipophilicity to tetraoxane. Attachment of higher cycloalkanes e.g. six and seven member dispirocycloalkane ring (cyclohexane or cycloheptane) to tetraoxane ring enhanced effectiveness of tetraoxanes than that of lower cycloalkanes e.g. five member dispirocycloalkane ring (cyclopentane) towards their antimalarial activity. Chloro group substituted dispirotetraoxane become less active than corresponding unsubstituted dispirotetraoxanes.

\section{Conclusion}

A novel series of compounds with potent antimalarial activity has been developed. Designed molecules have the possibility to introduce chemical diversity around the core skeleton to generate newer and potent molecules.

\section{Acknowledgement}

The authors are thankful to All India Council for Technical Education (AICTE), New Delhi for providing MODROPS project assistance to set up antimalarial screening facilities at Department of Pharmaceutical Sciences, Dibrugarh University, Dibrugarh, Assam, India. The authors also are thankful to S.A.I.F., Punjab University, Chandigarh, India for providing spectroscopic data.

\section{References}

Amewu R, O'Neill PM, Stachulski A, Ellis G, Ward SA. Dispiro tetraoxane compounds. United State Patent 0023551A1, 2013.

Casteel DA. Antimalarial agents. In: Burger's medicinal chemistry and drug discovery. $5^{\text {th }}$ ed. Vol. 5. USA, Wiley Interscience Publication, 1997, pp 3-75.

Coates J. Interpretation of infrared spectra: A practical approach. In: Encyclopedia of analytical chemistry. Meyers RA (ed.). USA, John Wiley and Sons Ltd, 2000, pp 10815-37.

Dong Y, Matile H, Chollet J, Kaminsky R, Wood JK, Vennerstrom JL. Synthesis and antimalarial activity of 11 dispiro1,2,4,5-tetraoxane analogues of WR 148999. 7,8,15,16tetraoxadispiro[5.2.5.2] hexadecanes substituted at the 1 and 10 positions with unsaturated and polar functional groups. J Med Chem. 1999; 42: 1477-80.

Kumawat MK, Singh UP, Singh B, Prakash A, Chetia D. Synthesis and antimalarial activity evaluation of 3-(3-(7chloroquinolin-4-ylamino)propyl)-1,3-thiazinan-4-one derivatives. Arab J Chem. 2011. 
Liu Y, Lu WQ, Cui KQ, Luo W, Wang J, Guo C. Synthesis and biological activities of novel artemisinin derivatives as cysteine protease falcipain-2 inhibitors. Arch Pharm Res. 2012; 35: 1525-31.

Mathieson DW. Interpretation of organic spectra. New York, Academic Press, 1965.

O'Neill PM, Amewu RK, Nixon GL, Garah FB, Mungthin M, Chadwick J, Shone AE, Vivas L, Lander $\mathrm{H}$, Barton V, Muangnoicharoen S, Bray PG, Davies J, Park BK, Wittlin S, Brun R, Preschel M, Zhang K, Ward SA. Identification of a 1,2,4,5-tetraoxane antimalarial drug-development candidate (RKA182) with superior properties to the semisynthetic artemisinins. Angew Chem Int Ed. 2010; 49: 5693-97.

O'Neill PM, Ellis GL, Amewu R, Hall C, Rimmer K, Ward SA. An efficient route into synthetically challenging bridged achiral 1,2,4,5-tetraoxanes with antimalarial activity. Bioorg Med Chem Lett. 2008; 18: 1720-24.

O'Neill PM, Ellis GL, Amewu R, Sabbani RS, Stocks PA, Shone A, Stanford D, Gibbons P, Davies J, Vivas L, Charnaud S, Bongard E, Hall C, Rimmer K, Lozanom S, Jesus M, Gargallo D, Ward SA. Two-step synthesis of achiral dispiro-1,2,4,5tetraoxanes with outstanding antimalarial activity, low toxicity, and high-stability profiles. J Med Chem. 2008; 51: 2170-77.

Oliveira R, Newton AS, Guedes RC, Miranda D, Amewu RK, Srivastava A, Gut J, Rosenthal PJ, O'Neill PM, Ward SA, Lopes F, Moreira R. An endoperoxide-based hybrid approach to deliver falcipain inhibitors inside malaria parasites. Chem Med Chem. 2013; 8: 1528-36.

Opsenica I, Opsenica D, Smith KS, Milhous WK, Solaja BA. Chemical stability of the peroxide bond enables diversified synthesis of potent tetraoxane antimalarials. J Med Chem. 2008; 51: 2261-66.

Pasto DJ, Johnson CR, Miller MJ. Experiments and techniques in organic chemistry. New Jersey, Prentice Hall, 1992.

Silverstein RM, Webster FX. Spectrometric identification of organic compounds. New York, John Wiley and Sons Ltd., 1963.

Terent'ev AO, Borisov DA, Yaremenko IA. General methods for the preparation of 1,2,4,5-tetraoxanes: Key structures for the development of peroxidic antimalarial agents. Chem Heterocycl Compd. 2012; 48: 55-58.

Trager W, Jensen JB. Human malaria parasites in continuous culture. Science 1976; 193: 673-75.

Vennerstrom JL, Dong Y, Andersen SL, Ager AL, Fu H, Miller RE, Wesche DL, Kyle DE, Gerena L, Walters SM, Wood JK, Edwards G, Holme AD, McLean WG, Milhous WK. Synthesis and antimalarial activity of sixteen dispiro-1,2,4,5tetraoxanes: Alkyl-substituted 7,8,15,16-tetraoxadispiro [5.2.5.2] hexadecanes. J Med Chem. 2000; 43: 2753-58.

Vennerstrom JL, Hong-Ning Fu J, Ellis WY, Ager AL, Wood JK, Andersen SL, Gerena L, Milhoust WK. Dispiro-1,2,4,5tetraoxanes: A new class of antimalarial peroxides. J Med Chem. 1992; 35: 3023-27.

\section{Author Info \\ Mukesh Kumar Kumawat (Principal contact) \\ I e-mail: phmukesh@gmail.com}

